\title{
COMPARISON BETWEEN THE ROLE OF TRANSABDOMINAL ULTRASOUND VERSUS TRANSVAGINAL ULTRASOUND IN EVALUATION OF PLACENTAL INVASION IN CASES OF PLACENTA PREVIA ANTERIOR WALL WITH PREVIOUS UTERINE SCAR
}

By

\author{
Abd-Elmonsef A. Sedek, Awad M. Awad and Mohammed A. Nafez \\ Department of Obstetrics and Gynecology \\ Faculty of Medicine, Alazhar University
}

\begin{abstract}
Background: Accurate antenatal diagnosis of an abnormally invasive placenta (AIP), allowing multidisciplinary management at the time of delivery, has been shown to improve maternal and fetal outcomes. Placenta previa and previous cesarean section are the two most important known risk factors for AIP.

Objective: Comparison between the role of transabdominal ultrasound (TAS) versus transvaginal ultrasound (TVS) in evaluation of placental invasion in cases of placenta previa anterior wall with previous uterine scar applying the unified ultrasonography descriptors suggested by the European working group on abnormally invasive placenta "EW-AIP".
\end{abstract}

Patients and Methods: Fifty pregnant women with persistent placenta previa (after 28 weeks' gestation) were prospectively enrolled into this study. Both transabdominal and transvaginal ultrasound were performed by two different operators who were blinded to the results of each other. The placenta was studied as regarding the exact localization and the unified descriptors were applied and evaluated by TAS and TVS. The ultrasound findings were analyzed with reference to the final diagnosis made during cesarean delivery and histopathological examination .

Results: Abnormally invasive placenta and its variants were found in 43 patients at the time of cesarean delivery, and were later confirmed by histopathological evaluation. As regards Grey-scale criteria; the accuracy of detection of the loss of the retro placental clear zone was $76 \%$ by TVS and $54 \%$ by TAS, while that of the abnormal placental lacunae was $92 \%$ by TVS and $88 \%$ by TAS. Myometrial Thinning detection accuracy was $66 \%$ by TVS and $72 \%$ by TAS, and Doppler assessment showed that the accuracy of detection of the uterovesical hyper vascularity was $84 \%$ by TVS and $88 \%$ by TAS. The detection of bridging vessels was $76 \%$ by TVS and $75 \%$ by TAS. The overall accuracy of detection of TAS was $91 \%$, whereas that of TVS was about $97.1 \%$.

Conclusion: Both transabdominal and trasnvaginal ultrasound were complementary to each other with an upper hand to transvaginal ultrasound, with the safety of TVS being confirmed. The unified descriptors were found to be reliable in accurate diagnosis.

Key words: Transabdominal, transvaginal ultrasound, placental invasion, Previa anterior wall, uterine Scar. 


\section{INTRODUCTION}

Placental attachment disorder (PAD) or morbidly adherent placenta (MAP) or the most recent synonym abnormally invasive placenta (AIP) encompasses a spectrum of conditions characterized by abnormal adherence of the placenta to the implantation site, with three variants classified according to their degree of trophoblastic invasion through the myometrium and the uterine serosa: placenta accreta, increta and percreta (Jauniaux and Bhide, 2018).

Morbidly adherent placenta (MAP) is generally associated with excess blood loss, bladder injuries and hysterectomies, and its incidence has increased significantly over the last 50 years (Wortman et al., 2013).

Maternal mortality from placenta accrete is estimated to be 6-7\% regardless of the type of the operation (Angstmann et al., 2010).

Despite the modern advances in imaging techniques, no single diagnostic technique affords complete assurance for the presence or absence of placenta accreta (Amin, 2019).

Antenatal diagnosis of MAP and multidisciplinary team approaches has the potential of reducing maternal and fetal intrapartum complications. This includes less maternal blood loss, with fewer transfusion requirements, reducing the rate of hysterectomy, intra operative urologic and gastrointestinal injuries and maternal deaths (Warshak et al., 2010 and Abuhamad, 2013).

According to Mazumder et al. (2017), the safe use of transvaginal ultrasound in cases of placenta previa has been confirmed, and it has been found that transvaginal ultrasonography is superior to Transabdominal sonography in the diagnosis of placenta previa.

Transabdominal ultrasound and transvaginal ultrasound are complementary for diagnosis; also transvaginal ultrasound is safe in cases of placenta previa and allows complete examination of the lower uterine segment. The European Working Group on Abnormally Invasive Placenta (EW-AIP) aimed to advance diagnosis and treatment and to promote research and knowledge on AIP in order to improve comparability of future studies, to increase diagnostic capabilities and to facilitate international collaboration; the EW-AIP here proposes standardized definitions of the AIP imaging descriptors (Collins et al., 2016).

The present work aimed to compare between the role of transabdominal ultrasound versus transvaginal ultrasound in evaluation of placental invasion in cases of placenta previa anterior wall with previous uterine scar applying the criteria of the "EW-AIP", and to evaluate the sensitivity and specificity of each criterion by comparing them with the final outcome of pregnancy.

\section{PATIENTS AND METHODS}

This study was carried out at $\mathrm{Al}$ Azhar university hospitals, in the period between October 2018 and April 2019, where 50 pregnant women with persistent placenta previa (after 28 weeks' gestation), were prospectively enrolled into this study.

The study included pregnant women in the reproductive age group (18-45) diagnosed persistent placenta previa anterior wall after 28 weeks of gestation, 
with history of previous caesarian Section and/or any other type of uterine surgeries, all of these women were admitted and have their operations of delivery performed at $\mathrm{Al}$ Azher university hospitals.

However, placenta previa posterior wall and unscarred uterus were excluded from the study.

\section{Each patient in this study was subjected to:}

- Full history taking including Personal history (name, age, file number) Obstetric history (number of C.S, abortion, placenta previa in previous pregnancy, history of ectopic, medical disorder with pregnancy and number of living children), present history (complain, gestational age, medical disorder in present pregnancy and history of ante partum hemorrhage) past history (postpartum sepsis, postpartum hemorrhage \& chronic diseases).

- Informed consent was obtained before scanning.

- Intraoperative data including: placental site, spontaneous separation, placental invasion into the bladder and other surrounding organs, uterotonic administration, bladder, ureteric or bowel injury, blood loss and blood transfusion, conservative management to avoid hysterectomy, need for Intensive Care Unit admission.

Postoperative data including: postoperative hemoglobin level and other labs postoperative blood transfusion need for intensive care unit admission.
- Histopathological examination in cases of hysterectomy : definitive diagnosis of abnormally invasive placenta was made at delivery when the myometrium was seen to be invaded by the placenta, and the pathological examination of the removed uterus showed the villi attached to the myometrium without intervening decidua (accrete), invading into the myometrium (increta) or reaching the serosa (percreta). Complete imaging using all diagnostic techniques (grayscale, color Doppler) by both transabdominal and transvaginal by two expert operators, then an offline analysis of the acquired images \& volumes was done. Placenta was examined while the bladder is partially full about $300 \mathrm{ml}$ for adequate visualization and precise localization. The examined placenta was considered to be suspicious of abnormal invasion in case of having one or more of the unified descriptors described by the European working Group on Abnormally Invasive Placenta "EWAIP":

\section{D grayscale:}

- Loss of 'clear zone' Loss, or irregularity, of hypoechoic plane in myometrium underneath placental bed ('clear zone').

- Abnormal placental lacunae: Presence of numerous lacunae including some that are large and irregular often containing turbulent flow visible on grayscale imaging.

- Bladder wall interruption: Loss or interruption of bright bladder wall (hyperechoic band or 'line' between uterine serosa and bladder lumen). 
- Myometrial thinning: Thinning of myometrium overlying placenta to $<1$ $\mathrm{mm}$ or undetectable.

- Placental bulge: Deviation of uterine serosa away from expected plane, caused by abnormal bulge of placental tissue into neighboring organ, typically bladder; uterine serosa appears intact but outline shape is distorted.

- Focal exophytic mass: Placental tissue seen breaking through uterine serosa and extending beyond it; most often seen inside filled urinary bladder.

\section{D color Doppler:}

- Uterovesical hypervascularity: Striking amount of color Doppler signal seen between myometrium and posterior wall of bladder; this sign probably indicates numerous, closely packed, tortuous vessels in that region.

- Subplacental hypervascularity: Striking amount of color Doppler signal seen in placental bed; this sign probably indicates numerous, closely packed, tortuous vessels in that region .

- Bridging vessels: Vessels appearing to extend from placenta, across myometrium and beyond serosa into bladder or other organs; often running perpendicular to myometrium .

- Placental lacunae feeder vessels: Vessels with high-velocity blood flow leading from myometrium into placental lacunae, causing turbulence upon entry.

\section{D ultrasound and power Doppler:}

- Intraplacental hypervascularity: complex,irregular arrangement of numerous placental vessels, exhibiting tourtuous courses and varying calibers.

- Placental bulge (as in 2D).

- Focal exophytic mass (as in 2D).

- Uterovesicalhypervacularity (as in 2D).

- Bridging vessels (as in 2D).

Every criterion descriptor was assessed both abdominally and vaginally and both assessments will be evaluated separately. The placenta was imaged with a sufficient bladder volume to clearly visualize the serosa-bladder interface, and the resistance index of flow within the abnormal lacunae and any newly formed vessels over the serosa-bladder border was measured in at least three different locations to obviate selection bias, with the lowest value being used for analysis. To analyze the angioarchitecture of the lower uterine segment and placenta, a 2D power Doppler examination targeting to this region was carried out and the views were successively evaluated: the lateral view was used to observe the intraplacental vasculature and serosabladder complex along the sagittal axis of the maternal pelvis, and the basal view illustrated the serosa-bladder interface in a 90॰rotation of the lateral view (observing from the direction of the bladder). All the pregnancies enrolled in this study were delivered by Cesarean section at Al Azhar University hospitals with full availability of information on the delivery. 


\section{RESULTS}

The accuracy of detection of the loss of the retroplacental clear zone was $76 \%$ by TVS and $54 \%$ by TAS (Table 1 ).

Table (1): Comparison of the accuracy between TAS and TVS as regards loss of retroplacental clear zone

\begin{tabular}{|c|c|c|c|c|c|}
\hline \multicolumn{3}{|r|}{ Clear zone TVS } & \multirow{2}{*}{$\begin{array}{c}\text { Correct } \\
26 \\
\end{array}$} & \multirow{2}{*}{$\begin{array}{c}\text { Incorrect } \\
1 \\
\end{array}$} & \multirow{2}{*}{$\begin{array}{c}\text { Total } \\
27 \\
\end{array}$} \\
\hline \multirow{6}{*}{$\begin{array}{l}\text { Clear zone } \\
\text { TAS }\end{array}$} & \multirow[t]{3}{*}{ Correct } & Count & & & \\
\hline & & $\%$ within Clear.zone.TAS & $96.3 \%$ & $3.7 \%$ & $100.0 \%$ \\
\hline & & $\%$ within Clear.zone.TVS & $68.4 \%$ & $8.3 \%$ & $54.0 \%$ \\
\hline & \multirow[t]{3}{*}{ Incorrect } & Count & 12 & 11 & 23 \\
\hline & & $\%$ within Clear.zone.TAS & $52.2 \%$ & $47.8 \%$ & $100.0 \%$ \\
\hline & & $\%$ within Clear.zone.TVS & $31.6 \%$ & $91.7 \%$ & $46.0 \%$ \\
\hline \multirow{3}{*}{\multicolumn{2}{|c|}{ Total }} & Count & 38 & 12 & 50 \\
\hline & & $\%$ within Clear.zone.TAS & $76.0 \%$ & $24.0 \%$ & $100.0 \%$ \\
\hline & & $\%$ within Clear.zone.TVS & $100.0 \%$ & $100.0 \%$ & $100.0 \%$ \\
\hline
\end{tabular}

\begin{tabular}{|l|l|}
\hline \multicolumn{2}{|l|}{ Chi-Square Test } \\
\hline & p-value \\
\hline McNemar Test & $\mathbf{. 0 0 6}$ \\
\hline
\end{tabular}

Detection of abnormal placental lacunae was $92 \%$ by TVS and $88 \%$ by TAS (Table 2 ).

Table (1): Comparison of the accuracy between TAS and TVS as regards abnormal placental lacuna

\begin{tabular}{|c|c|c|c|c|c|}
\hline \multicolumn{3}{|c|}{ 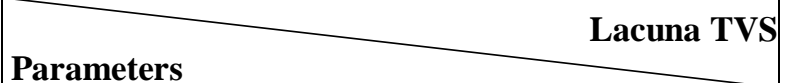 } & \multirow{2}{*}{$\begin{array}{c}\text { Correct } \\
43\end{array}$} & \multirow{2}{*}{$\begin{array}{c}\text { Incorrect } \\
3 \\
\end{array}$} & \multirow{2}{*}{$\begin{array}{c}\text { Total } \\
46\end{array}$} \\
\hline \multirow{6}{*}{$\begin{array}{l}\text { Lacuna } \\
\text { TAS }\end{array}$} & \multirow[t]{3}{*}{ Correct } & Count & & & \\
\hline & & $\%$ within Lacuna.TAS & $93.5 \%$ & $6.5 \%$ & $100.0 \%$ \\
\hline & & $\%$ within LacunaTVS & $97.7 \%$ & $50.0 \%$ & $92.0 \%$ \\
\hline & \multirow[t]{3}{*}{ Incorrect } & Count & 1 & 3 & 4 \\
\hline & & $\%$ within Lacuna.TAS & $25.0 \%$ & $75.0 \%$ & $100.0 \%$ \\
\hline & & $\%$ within LacunaTVS & $2.3 \%$ & $50.0 \%$ & $8.0 \%$ \\
\hline \multirow{3}{*}{\multicolumn{2}{|c|}{ Total }} & Count & 44 & 6 & 50 \\
\hline & & $\%$ within Lacuna.TAS & $88.0 \%$ & $12.0 \%$ & $100.0 \%$ \\
\hline & & $\%$ within LacunaTVS & $100.0 \%$ & $100.0 \%$ & $100.0 \%$ \\
\hline
\end{tabular}

\begin{tabular}{|l|l|}
\hline \multicolumn{2}{|c|}{ Chi-Square Test } \\
\hline & p-value \\
\hline McNemar Test & .671 \\
\hline a. Binomial distribution used. \\
\hline
\end{tabular}


The accuracy of detection of myometrial thining was $66 \%$ by TVS and $72 \%$ by TAS (Table 3).

Table (2): Comparison of the accuracy between TAS and TVS as regards myometrial thinning

\begin{tabular}{|c|c|c|c|c|c|}
\hline \multicolumn{3}{|l|}{ Parameters } & \multirow{2}{*}{$\begin{array}{c}\text { Correct } \\
29\end{array}$} & \multirow{2}{*}{$\begin{array}{c}\text { Incorrect } \\
4 \\
\end{array}$} & \multirow{2}{*}{$\begin{array}{c}\text { Total } \\
33 \\
\end{array}$} \\
\hline \multirow{6}{*}{$\begin{array}{l}\text { Myometrial } \\
\text { thinning } \\
\text { TAS }\end{array}$} & \multirow[t]{3}{*}{ Correct } & Count & & & \\
\hline & & $\%$ within Myom.thin.TAS & $87.9 \%$ & $12.1 \%$ & $100.0 \%$ \\
\hline & & $\%$ within Myom.Thin.TVS & $80.6 \%$ & $28.6 \%$ & $66.0 \%$ \\
\hline & \multirow[t]{3}{*}{ Incorrect } & Count & 7 & 10 & 17 \\
\hline & & $\%$ within Myom.thin.TAS & $41.2 \%$ & $58.8 \%$ & $100.0 \%$ \\
\hline & & $\%$ within Myom.Thin.TVS & $19.4 \%$ & $71.4 \%$ & $34.0 \%$ \\
\hline \multirow{3}{*}{\multicolumn{2}{|c|}{ Total }} & Count & 36 & 14 & 50 \\
\hline & & $\%$ within Myom.thin.TAS & $72.0 \%$ & $28.0 \%$ & $100.0 \%$ \\
\hline & & $\%$ within Myom. Thin.TVS & $100.0 \%$ & $100.0 \%$ & $100.0 \%$ \\
\hline
\end{tabular}

\begin{tabular}{|l|l|}
\hline Chi-Square Test \\
\hline & $\mathrm{p}$-value \\
\hline McNemar Test & .547 \\
\hline
\end{tabular}

Detection of the uterovesical hypervascularity was $84 \%$ by TVS and $88 \%$ by TAS (Table 4).

Table (3): Comparison of the accuracy between TAS and TVS as regards Uterovesical vascularity

\begin{tabular}{|c|c|c|c|c|c|}
\hline \multicolumn{3}{|r|}{ UV.vascularity.TVS } & \multirow{2}{*}{$\begin{array}{c}\text { Correct } \\
41 \\
\end{array}$} & \multirow{2}{*}{$\begin{array}{c}\text { Incorrect } \\
1 \\
\end{array}$} & \multirow{2}{*}{$\begin{array}{c}\text { Total } \\
42 \\
\end{array}$} \\
\hline \multirow{6}{*}{$\begin{array}{l}\text { Utero-vesical } \\
\text { vascularity } \\
\text { TAS }\end{array}$} & \multirow[t]{3}{*}{ Correct } & Count & & & \\
\hline & & \% within UV.vascularty.TAS & $97.6 \%$ & $2.4 \%$ & $100.0 \%$ \\
\hline & & $\%$ within UV.vascularity.TVS & $93.2 \%$ & $16.7 \%$ & $84.0 \%$ \\
\hline & \multirow[t]{3}{*}{ Incorrect } & Count & 3 & 5 & 8 \\
\hline & & $\%$ within UV.vascularty.TAS & $37.5 \%$ & $62.5 \%$ & $100.0 \%$ \\
\hline & & \% within UV.vascularity.TVS & $6.8 \%$ & $83.3 \%$ & $16.0 \%$ \\
\hline \multirow{3}{*}{\multicolumn{2}{|c|}{ Total }} & Count & 44 & 6 & 50 \\
\hline & & \% within UV.vascularty.TAS & $88.0 \%$ & $12.0 \%$ & $100.0 \%$ \\
\hline & & \% within UV.vascularity.TVS & $100.0 \%$ & $100.0 \%$ & $100.0 \%$ \\
\hline
\end{tabular}

\begin{tabular}{|l|l|}
\hline Chi-Square Test \\
\hline & $\mathrm{p}$-value \\
\hline McNemar Test & .617 \\
\hline
\end{tabular}


Detection of bridging vessels was $76 \%$ by TVS and $75 \%$ by TAS (Table 5 ).

Table (5): Comparison of the accuracy between TAS and TVS as regards Bridging Vessels

\begin{tabular}{|c|c|c|c|c|c|}
\hline \multicolumn{3}{|c|}{\begin{tabular}{|lc} 
Parameters & Bridge.V.TVS \\
\end{tabular}} & \multirow{2}{*}{$\begin{array}{c}\text { Correct } \\
35\end{array}$} & \multirow{2}{*}{$\frac{\text { Incorrect }}{2}$} & \multirow{2}{*}{$\begin{array}{c}\text { Total } \\
37 \\
\end{array}$} \\
\hline \multirow{6}{*}{$\begin{array}{l}\text { Bridging } \\
\text { Vessels } \\
\text { TAS }\end{array}$} & \multirow[t]{3}{*}{ Correct } & Count & & & \\
\hline & & $\%$ within Bridge.V.TAS & $94.6 \%$ & $5.4 \%$ & $100.0 \%$ \\
\hline & & $\%$ within Bridge.V.TVS & $92.1 \%$ & $16.7 \%$ & $74.0 \%$ \\
\hline & \multirow[t]{3}{*}{ Incorrect } & Count & 3 & 10 & 13 \\
\hline & & $\%$ within Bridge.V.TAS & $23.1 \%$ & $76.9 \%$ & $100.0 \%$ \\
\hline & & $\%$ within Bridge.V.TVS & $7.9 \%$ & $83.3 \%$ & $26.0 \%$ \\
\hline \multirow{3}{*}{\multicolumn{2}{|c|}{ Total }} & Count & 38 & 12 & 50 \\
\hline & & $\%$ within Bridge.V.TAS & $76.0 \%$ & $24.0 \%$ & $100.0 \%$ \\
\hline & & $\%$ within Bridge.V.TVS & $100.0 \%$ & $100.0 \%$ & $100.0 \%$ \\
\hline
\end{tabular}

\begin{tabular}{|l|l|}
\hline Chi-Square Test \\
\hline & p-value \\
\hline McNemar Test & 1.000 \\
\hline
\end{tabular}

The overall accuracy of detection of TAS was $91.5 \%$ whereas that of TVS was about 97. 5\% (Table 6).

Table (6): Comparison between the overall accuracy of TAS vs TVS.

\begin{tabular}{|l|l|l|}
\hline Parameter Comparison & Transabdominal ultrasound & \multicolumn{1}{|c|}{$\begin{array}{c}\text { Transvaginal } \\
\text { ultrasound }\end{array}$} \\
\hline Sensitivity & 94.2 & 98.1 \\
\hline Specificity & 85 & 93.8 \\
\hline Positive predictive value & 96 & 99 \\
\hline Negative predictive value & 66.7 & 88.2 \\
\hline Accuracy & 91.5 & 97.5 \\
\hline Validity (out of 43 patients) & Detected 37 & Detected 42 \\
\hline
\end{tabular}

\section{DISCUSSION}

Prenatal diagnosis of MAP and its variants can help reduce maternal/fetal morbidity and mortality by allowing us to choose the best time and place of birth. Multidisciplinary surgical management, neonatal intensive care, prophylactic hypogastric artery balloon occlusion, uterine artery embolization and an adequate number of blood units available in the operating room can only be achieved effectively through early detection of the placental pathology (Cali et al., 2013).
Several authors have reviewed the diagnostic accuracy of sonographic criteria for placenta accretes. The risk of performing an unnecessary hysterectomy (false positive) or the risk of secondary bleeding following attempted placental removal (false negative) should always be considered. An evaluation based on sensitivity and specificity is not sufficient to legitimize the use of diagnostic criteria; assessing PPV and NPV is mandatory to planning appropriate management and information of patients (Wong et al., 2012). 
A review of the last decade's literature shows an increasing incidence of placenta accreta, mainly due to more frequent CSs. In almost all cases, abnormal placental invasion is at the site of previous uterine scar.Other risk factors, which are related less strongly to MAP, include advanced maternal age, myometrial damage due to a myomectomy with endometrial entry, heavy curettage with secondary Asherman syndrome, submucosal myoma (Cali et al., 2013).

Women atmost increased risks of abnormally invasive placenta are, however, those who had a previous CS with a placenta previa overlying the previous uterine scar (Comstock and Bronsteen, 2014).

The diagnosis of morbidly adherent placenta involves a number of different ultrasound variables, some qualitative and others that have been quantified.

Several studies have assessed the predictive value of different ultrasound markers of AIP. However, the performance of these markers shows considerable.

Variability among studies using the same signs. These differences have been attributed previously to a combination of limited sample size, retrospective design and variability of study inclusion criteria and eventual diagnosis of AIP (D'Antonio et al., 2013).

Furthermore, as with all diagnostic techniques reliant on subjective opinion, the recorded presence or absence of each sign will be influenced by the operator's interpretation of what constitutes that marker.
This is particularly important to clinicians, who may not have much experience with ultrasonography of the placenta or diagnosing AIP. Additionally, there is no published consensus on the definition of the ultrasound markers used commonly for AIP. Many signs have been described under different names, and in other cases the same term has been used for different findings (Collins et al., 2016).

The 'European Working Group on Abnormally Invasive Placenta' (EW-AIP) is an international non-profit group, currently consisting of 29 obstetricians, gynecologists, pathologists, anesthesiologists and basic science researchers from 11 European countries.

The aim of the group is to advance diagnosis and treatment and to promote research and knowledge on AIP. To improve comparability of future studies, to increase diagnostic capabilities and to facilitate international collaboration, the EW-AIP here proposes standardized definitions of the AIP imaging descriptors.

These standardized definitions were produced by analysis of all 23 studies included in a recent systematic review of the antenatal sonographic diagnosis of AIP (Collins et al., 2016).

The various wordings were unified into a set of 11 descriptors, six for 2D grayscale ultrasound, four for 2D color Doppler and one for 3D power Doppler, Importance was placed on defining each sign unambiguously, irrespective of opinions regarding the predictive value of each descriptor.

This study aims to compare between the roles of Transabdominal ultrasound vs 
Transvaginal ultrasound in assessment of placental invasion in cases of placenta previa anterior wall with previous uterine scar applying the unified descriptors of the "EW-AIP" and also to evaluate the sensitivity and specificity of each criterion by comparing them with the final outcome of pregnancy.

The results showed that regarding the presence of abnormal placental lacunae. They showed Sensitivity 93.0\%, specificity $66.7 \%$, PPV $97.6 \%$, NPV $85.7 \%$, accuracy $90 \%$ by transabdominal ulrasonography (TAS).

Sensitivity $88.4 \%$, specificity $85.7 \%$, PPV $97.4 \%$, NPV $85.7 \%$, accuracy $88.0 \%$ were detected by transvaginal ultrasonography (TVS).

The PPV of lacunae shows more variation from author to author than other signs, they were reported as sensitive and specific in some studies and no so in others.

This study agreed with Comstock and Bronsteen (2014) where they found them to be $93 \%$ sensitive in women at 20 weeks of gestation and beyond with a 93\% PPV; whereas Cali et al. (2013) found that presence of abnormal lacune showed Sensitivity $73.0 \%$, specificity $86.7 \%$.

In a systematic review, the overall pooled sensitivity and specificity from 13 studies of lacunar spaces diagnosing MAP was $77 \%$ and $95 \%$, respectively, with an overall diagnostic accuracy of $88 \%$ (D’Antonio et al., 2013).

Regarding loss of the retroplacental clear zone, this study showed Sensitivity $51.2 \%$, specificity $71.4 \%$, PPV $91.7 \%$, NPV $19.2 \%$, accuracy $54.0 \%$ by TAS.
Sensitivity $74.4 \%$, specificity $85.7 \%$, PPV 97.0\%, NPV 35.3\%, accuracy $76.0 \%$ wer by TVS.

Cali et al. (2013) showed that the loss of retropalcental clear zone had Sensitivity $90 \%$, specificity $81 \%$, PPV 57\%, NPV $97 \%$.

However, Romeo et al. (2019) stated that the loss of the retroplacental clear zone accounts for the majority of False Positive results and the criterion should not be used by itself to make the diagnosis.

Bhide et al. (2017) found absence of the clear space in $37(65 \%)$ women without placenta accreta and in $100 \%$ of those women with it. Hence, it is sensitive but not specific. The primary use of the clear space appears to be that its presence effectively excludes placenta accreta because it has a high negative predictive value (NPV).

Regarding interruption of the bladder wall, this study showed it to have sensitivity $4.7 \%$, specificity $100.0 \%$, PPV $100.0 \%$, NPV $14.6 \%$, accuracy $18.0 \%$ by TAS and Sensitivity 9.3\%, specificity $100 \%$, PPV 100\%, NPV $15.2 \%$, accuracy $22.0 \%$ by TVS which agreed with Comstock and Bronsteen (2014) where this finding had Sensitivity 20\%, PPV $75 \%$ and Bhide et al. (2017) Sensitivity $11 \%$, specificity $100 \%$ was unlike Cali et al. (2013) where this criterion showed Sensitivity $70 \%$, specificity $100 \%$, PPV $100 \%$, NPV $100 \%$.

The cause of the low sensitivity reported by Comstock \& Bronsteen (2014), and Bhide et al. (2017) may be that not all women had transvaginal ultrasound with the quite specific 
conditions used by Cali et al. (2013). In that large study the authors first determined that $300 \mathrm{ml}$ in the bladder resulted in the best visualization of the uterine-bladder interface and then instilled this amount into each woman's bladder.

Regarding the uterovesical hypervascualrity using Color Doppler Flow

This study shows Sensitivity $86.0 \%$, specificity $71.4 \%$, PPV $94.9 \%$, NPV $45.5 \%$, accuracy $84.0 \%$ by TAS and Sensitivity $93.0 \%$, specificity $57.1 \%$, PPV $93.0 \%$, NPV $57.1 \%$, accuracy $88.0 \%$ by TVS.

The sensitivity of this descriptor significantly increased using TVS, also this agreed with Cali et al. (2013) where they showed Sensitivity $95.0 \%$, specificity $100 \%$, PPV 100\%, NPV 97\%, regarding the presence of abnormal bridging vessels between the placenta and the bladder wall.

This study showed Sensitivity 69.8\%, specificity $100 \%$, PPV 100\%, NPV $35.0 \%$, accuracy $74.0 \%$ by TAS and Sensitivity $71.2 \%$, specificity $100 \%$, PPV $100 \%$, NPV $36.8 \%$, accuracy $76.0 \%$ by TVS which also confirmed by Cali et al. (2013).

Although no studies have been performed that directly compare the diagnostic accuracy of transabdominal vs transvaginal ultrasound in the setting of suspected placental invasion, transvaginal ultrasound allows for a more complete evaluation of the lower uterine segment and is the current recommended standard of care (Rac et al., 2015).

This study used aimed mainly to compare between the role of
Transabdominal ultrasound vs Transvaginal ultrasound in assessment of placental invasion in cases of placenta previa anterior wall with previous uterine scar applying the criteria of the "EWAIP".

Although no studies have been performed that directly compare the diagnostic accuracy of transabdominal vs transvaginal ultrasound in the setting of suspected placental invasion, transvaginal ultrasound allows for a more complete evaluation of the lower uterine segment and is the current recommended standard of care (Rac et al., 2015).

Throughout the period of this study, every patient who was enrolled has undergone both Transabdominal sonography and transvaginal sosngraphy and every one of the unified descriptors was assessed via both modalities, the accuracy of both modalities was calculated regarding their ability to evaluate each one of the unified descriptors as follows the accuracy of detection of the loss of the retroplacental clear zone was $76 \%$ by TVS and $54 \%$ by TAS.

That of the abnormal placental lacunae was $92 \%$ by TAS and $88 \%$ by TVS. Myometrial Thinning detection accuracy was $66 \%$ by TAS and $72 \%$ by TVS; while the Doppler assessment showed that the accuracy of detection of the uterovesical hypervascularity was $84 \%$ by TAS and $88 \%$ by TVS; while the detection of bridging vessels was $76 \%$ by TAS and $75 \%$ by TVS.

From this we conclude thd accuracy of detection of the unified descriptors is quite close regarding TVS and TAS. However, 
TVS was found to be more accurate in the exact placental localization.

The overall accuracy of detection of TAS was $91 \%$ whereas that of TVS was about $97.1 \%$

Assigning a score in clinical practice may be helpful in the antenatal diagnosis of MAP and seems to be a key factor in reducing maternal and fetal morbidity and mortality, by allowing multidisciplinary counseling, and planning and timing of delivery.

Other studies suggested different scoring systems based on different criteria that would eventually enhance the ability of ultrasonogropahy to predict abnormal placental invasion and thus enhance the offered approach.

In conclusion, this study suggests that both transabdominal and transvaginal ultrasonographic modalities are complementary to each other, putting in mind that TVS had a slightly higher overall accuracy and was performed by a highly experienced operator.

Also the unified descriptors suggested by the EW-AIP were found to be of dependable accuracy as well.

An important point to be considered is that all the patients who were enrolled in this study and were exposed to transvaginal ultrasound, none of them experienced any attack of bleeding during the procedure which proves the profound safety of this modality confirming many previous studies.

AIP can be predicted as early as in the first trimester, and almost always confirmed in the second and third trimesters.
Grayscale ultrasonography, with or without color Doppler and performed both transabdominally and transvaginally, has been used widely for antenatal screening and diagnosis of AIP (Alfievic et al., 2016).

Many signs have been suggested, with reports varying as to their sensitivity and difficult to assess which are the most robust. To address this, the European Working Group on AIP (EW-AIP) produced a consensus proposal to standardize the ultrasound descriptions used to define each sign (Collins et al., 2016).

Such approach may facilitate better communication, and better evaluation of our diagnostic performance, in cases of suspected AIP.

According to Chantraine and Collins (2019), the safe use of transvaginal ultrasound in cases of placenta previa has been confirmed and it has been found that transvaginal ultrasonography is superior to transabdominal sonography in the diagnosis of placenta previa and invariably correct in ruling it out.

Cesarean scar pregnancy "CSP" is the main precursor of Abnormally Invasive placenta with its variants, its early detection in suspected cases as early as 6 weeks of pregnancy offers better outcome and even allows the opportunity for patient counseling as early as possible and even considering termination of pregnancy.

\section{CONCLUSION}

Transabdominal sonograhy and transvaginal sonography are complementary to each other, however transvaginal ultrasound was found to be of 
a slightly higher accuracy. Also, it has been confirmed that TVS is completely safe without any attack of bleeding for any of the patients during the procedure.

\section{REFERENCES}

1. Abuhamad, A. (2013): Morbidly adherent placenta. In Seminars in perinatology, Vol. 37, No. 5, pp. 359364, pbl. WB Saunders, USA.

2. Alfirevic, Z., Tang, A. W., Collins, S. L., Robson, S. C., \& Palacios-Jaraquemada, J. (2016): Pro forma for ultrasound reporting in suspected abnormally invasive placenta (AIP): an international consensus. Ultrasound in Obstetrics \& Gynecology,47(3): 276-278.

3. Amin, R. (2019): Comparison of accuracy of ultrasonography and magntic resonance imaging in prenatal diagnosis of placenta accreta. Indian Journal of Applied Research, 9(8): 2249-555.

4. Angstmann, Ben Nagi J, Ofili-Yebovi, D. Marsh, and Jurkovic D. (2010): First-trimester cesarean scar pregnancy evolving into placenta previa/accreta at term. Journal of ultrasound in medicine, 24(11): 15691573.

5. Bhide, A., Sebire, N., Abuhamad, A., Acharya, G., \& Silver, R. (2017): Morbidly adherent placenta: the need for standardization. Ultrasound in Obstetrics \& Gynecology, 49(5): 559-563.

6. Cal? G, Giambanco L, Puccio G and Forlani F. (2013): Morbidly adherent placenta: Evaluation of ultrasound diagnostic criteria and differentiation of placenta accreta from percreta. Ultrasound Obstetrics \& Gynecology: 41:406-12.

7. Chantraine, F. and Collins, S. L. (2019): Prenatal Ultrasound Imaging for
Placenta Accreta Spectrum (PAS): a Practical Guide. Current Obstetrics and Gynecology Reports, 8(3): 86-93.

8. Collins, S. L., Ashcroft, A., Braun, T., Calda, P., Langhoff- Roos, J., Morel, O., Stefanovic, V, Chantraine, F \& European Working Group on Abnormally Invasive Placenta (EWAIP). (2016): Proposal for standardized ultrasound descriptors of abnormally invasive placenta (AIP). Ultrasound in Obstetrics \& Gynecology, 47(3): 271275.

9. Comstock $\mathrm{CH}$ and Bronsteen RA (2014): The antenatal diagnosis of placenta accreta. BJOG, 121:171-81.

10. D'Antonio F, Iacovella $\mathrm{C}$ and Bhide $\mathrm{A}$ (2013): Prenatal identification of invasive placentation using ultrasound: systematic review and meta-analysis. Ultrasound Obstet Gynecol ., 42: 509517.

11. Jauniaux, E and Bhide, A. (2017): Prenatal ultrasound diagnosis and outcome of placenta previa accreta after cesarean delivery: a systematic review and meta-analysis. American Journal of Obstetrics and Gynecology, 217(1): 2736.

12. Mazumder, U., Kutubi, A. and Rouf, S. (2017): Updated Protocol for Management of Placenta Previa. Journal of Shaheed Suhrawardy Medical College, 9(1): 26-30.

13. Rac, M. W., Dashe, J. S., Wells, C. E., Moschos, E., McIntire, D. D. and Twickler, D. M. (2015): Ultrasound predictors of placental invasion: the Placenta Accreta Index. American journal of obstetrics and gynecology, 212(3): 343-e1.

14. Romeo, V., Sarno, L., Volpe, A., Ginocchio, M. I., Esposito, R., Mainenti, P. P., Liuzzi, R., 
D'Armiento, $M$ and Brunetti, A. (2019): US and MR imaging findings to detect placental adhesion spectrum (PAS) in patients with placenta previa: a comparative systematic study. Abdominal Radiology, 44(10): 33983407.

15. Warshak, C. R., Ramos, G. A., Eskander, R., Benirschke, K., Saenz, C. C., Kelly, T. F. and Resnik, R. (2010): Effect of predelivery diagnosis in 99 consecutive cases of placenta accreta.
Obstetrics and Gynecology, 115(1): 6569.

16. Wong HS, Cheung YK and Williams E (2012): Antenatal ultrasound assessment of placental/myometrial involvement in morbidly adherent placenta. Aust $\mathrm{N}$ Z J Obstet Gynaecol., 52: 67-72.

17. Wortman, AC., and James M.A (2013): "Placentaaccreta, increta, and percreta." Obstetrics and Gynecology Clinics 40.1: 137-154. 
المقارنة بين الموجات فوق الصوتية عن طريق البطن

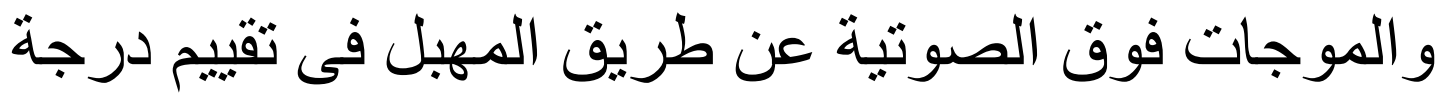

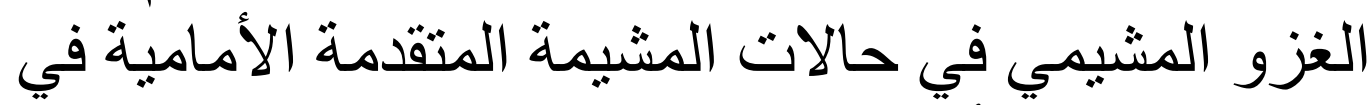
الأرحام ذو ات الات المنبة القديمة المتفمة

عبد المنصف عبد الحميد صديق، عوض محمود عوض، محمد علي ناقن قسم التوليا وأمر اض النساءـ كلية الطب - جامعة الأزهر

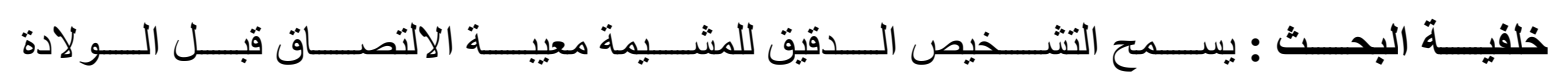

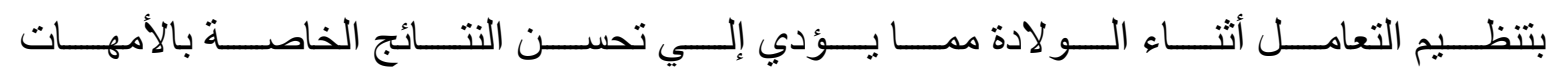

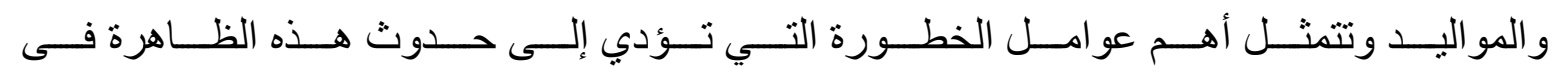

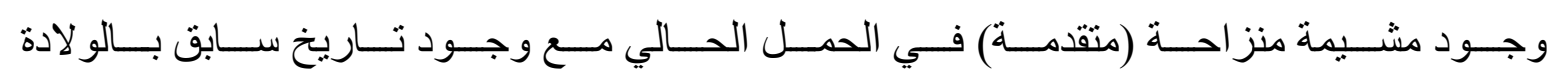
القيصرية.

الهــــف مــن البحــث: تهــدف هـــه الدر اســة الـــي المقارنــة بــين كفــاءة الموجــات فــوق

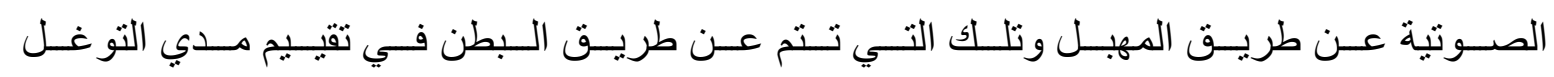

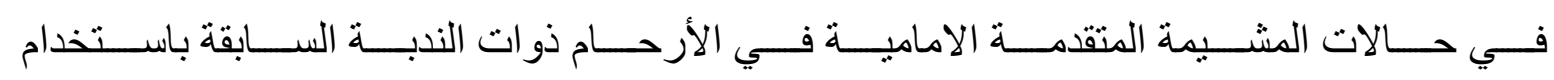

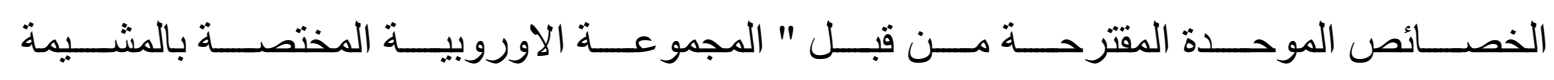

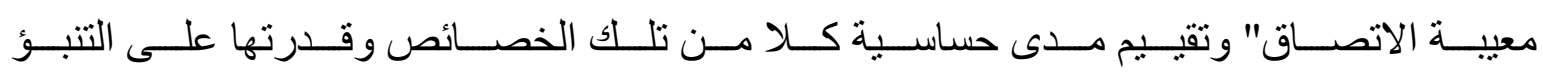
بوجود مشيمة معيبة الاتصاق ومقارنة ذلك بالنتائج الجر احية.

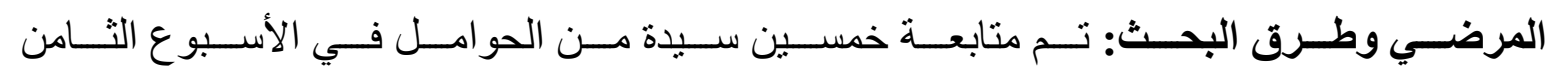

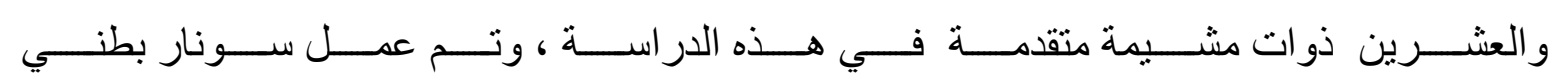

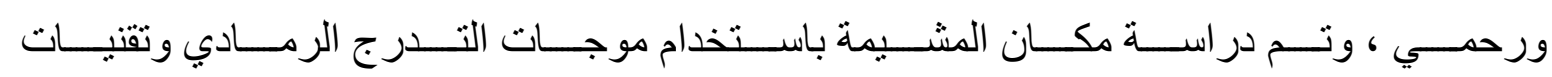

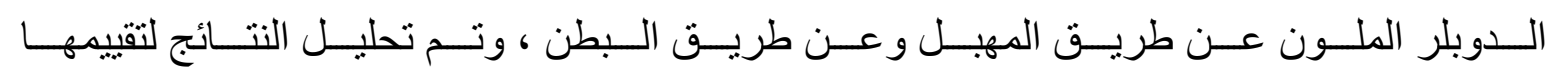
أنثاء الو لاده القيصرية و عمل فحص للأنسجة .

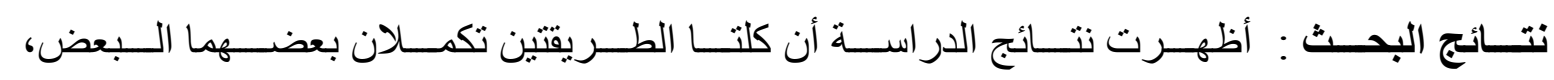

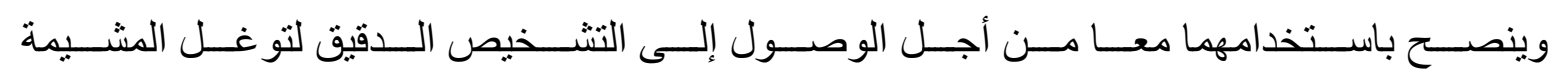

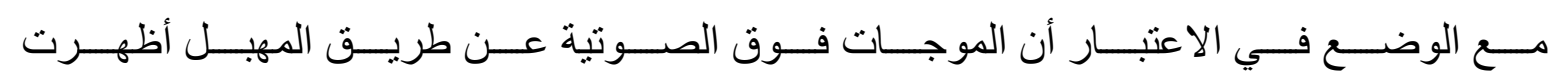




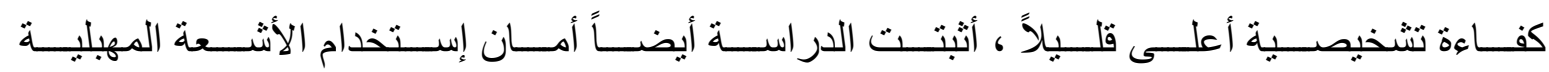

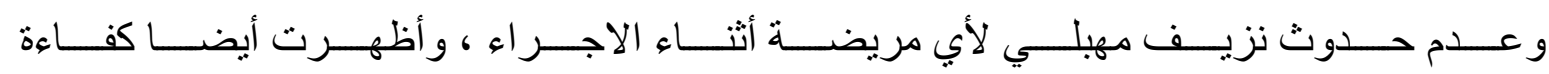

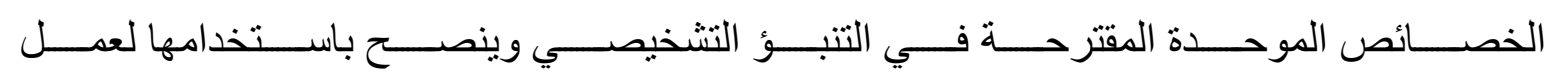
معادلة تتبؤية في المستقبل القريب.

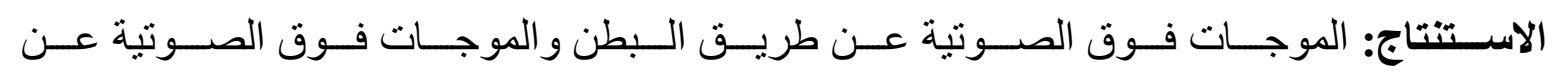

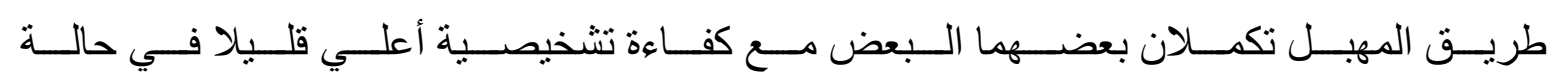

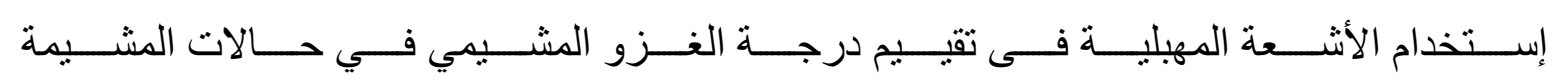
المتقدمة الأمامية في الأرحام ذوات الندبه القديمة. 